\title{
THE USE OF PREWRITING METHODS TO DEVELOP EFL STUDENTS' COMPETENCE IN WRITING
}

\author{
Magdahalena \\ STAIN PARE PARE \\ magdahalena_tjalla@yahoo.com
}

\begin{abstract}
The process approach becomes a choice for teachers to apply in the writing class rooms since this approach focuses on the connection of the writing topics to the students' experiences which makes the writing tasks meaningful to students (Yan, 20014). In process approach, students' composition is a product that should go through several stages: prewriting, writing, and post writing. In prewriting, there are several interesting activities that can be done in to improve students' writing skill: asking questions, discussing an interesting topic, taking notes, free writing, clustering, brainstorming, grouping, doing buzy group, outlining, completing notes based on pictures, making a list, making idea map, categorizing, and classifying (Oshima and Hogue, 1997; Harmer, 2004, Huizenga, et al.,1990). Some research have proved the significant role of process writing to improve students' skill in writing, Ho (2006) conducted a research on the effectiveness of using process approach in writing to primary school students of upper level and lower level through pre and post test, questionnaire, interview, and observation and found that process writing was able to develop the writing abilities and students' attitude towards writing in all levels of students. Hasan \& Akhand (2010) in their research combine the product approach and the process approach to teach ESL students in Bangladesh and revealed that the combination of the two approaches facilitate students to do writing tasks. Badger and White (2000) in Yan (2014) combine the process approach and the genre approach which he called process genre approach in their study and reported that this approach helped students study the relationship between purpose and form for a particular genre while they follow the stages in process writing: prewriting, drafting, revising, and editing. Using these steps develops students' awareness of different text types and of the composing process.
\end{abstract}

KEYWORDS: Writing, Prewriting Methods

\section{A. INTRODUCTION}

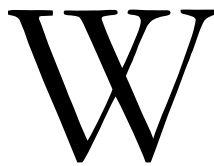

ritten language is distinguished from spoken language with it's feature of formality. It is completed with several rules to follow to make the reader

understand the author's message. The rules are in form of grammar, mechanics

such as the use of punctuations and capital letter. Academic writing, is also completed with special vocabularies that are different from the ones used in spoken language. These make writing difficult for most of the ESL and EFL students, even writing in their native language (Saud et al.:2005).

Comparing to speaking, in ESL classroom, students can speak confidently with few vocabularies. However, students can hardly write a meaningful paragraph even with the same 
amount of vocabulary that they can use when they speak. Moreover, most students think that the formality features of writing which consist of some rules makes it a boring activity. Students sometimes feel that it is difficult to write following the rules.

Mastering writing skill is a must for EFL students in Indonesia to complete their daily tasks and to complete their study. However, with the complexity of the rules of English writing whcih make students unmotivated and feel bored to write, it is hard for teacher to achieve the objective of teaching writing, The problem getting worse since students sometimes feel that writing activities are not meaningful for them. They can hardly relate the writing activities to their daily live. Mukminatien (2004:187)argues that the problem might be caused by the lack of exposure to the use of English writing in real-life situation.

Another problem happens in writing class is that many commercial textbooks used by the teachers discuss topics thatdo not have relationship with the students' cultural background (in Tomlinson, 2003). Such topics might not be interesting for students since they do not have background knowledge of the topics to write. Svinicki ( 2013) argues that background or prior knowledge is crucial in learning process since it helps students perceive and sometimes organize new information, as well as make connection for new information.

Many teachers in Indonesian universities still apply traditional method in teaching writing in which they ask students to write based on the model text and pay attention to the grammatical correctness. Students are assigned to do writing tasks to practice language. By dong this, teachers have excluded the context of the writing. Therefore, students are difficult to relate this activity to their own context and the purpose of the activity is not clear. Writing activities are mainly focused on language practice. Many educators would agree in a theory that learning and practicing language is more appealing to both students and teachers than learning language through extensive repetition and drilling. Moreover, many theories on language learning support the use of context to encourage language production (Hadley: 1993).

The traditional method of teaching writing considers writing as a product. Writing activity is done to produce a text which is grammatically correct. Language used in this activity is not to communicate but students use language for grammatical use.

The process approach becomes a choice for teachers to apply in the writing class rooms. The strength of this approach is the focus of writing tasks on the connection of the writing topic to the students' experience and their understanding of the process of writing comes at the time they write. This makes the writing tasks meaningful to students (Yan, 2014).

In process approach, students composition is a product that should go through several stages: prewriting, writing, and post writing. O'Donnel and Paiva (1993) argue that writing process is a recursive activity which means that the writer may need to go through the stages more than once. The writer sometimes needs to go back to the process that we have done 
until he can produce a finished composition.

Unlike in product approach, writing activities in process approach is not focused to produce a grammatical piece of writing, but to a process which consists of several stages to follow, in which students do brainstorming before writing and revising after writing. In other words in process approach, students are exposured to various classroom activities to promote the language use development (Hasan and Akhand, 2010).

If we apply a process approach, there are some steps to follow in composing a text. Brown ( 1984) divides the process of writing into three stages: prewriting, writing, and revising. In prewriting a writer does three things: thinking, planning, and preparing. This stage is done to give a writer an opportunity to collect ideas to write. In this stage, a writer also identifies his/her purpose of writing, audience to whom his/her writing is directed, and the topic of the writing. After finishing this stage, a writer can develop his/her ideas in a piece of writing by considering the purpose of writing as well as the audience to whom his/her writing is directed. Revising is done when a writer has finished the first draft of his/her writing by reorganizing and rewriting. The final step of the revising stages is proofreading. In this stage, all errors in grammar, usage, spelling, capitalization, and punctuation are checking carefully. The process will come to the end if all the stages have been done.

O'Donnel and Paiva (1993) explain the process of writing into several steps: thinking, planning, writing, revising, and editing. In thinking stage, a writer may do several strategies, such as discuss the topic with friends, takes notes the ideas comes in mind, or keep the idea in mind. In planning stage a writer can make outline of the ideas. The ideas are arranged in order. This arranged outline will be followed by the writer when he starts writing his text. Some writers write the ideas come in their mind to help them generate / produce/find out new ideas. They think while they write, and makes plan later. Another stage of writing is revising. In this stage, the writer look back the text that has been written and ask some questions related to the content of the text. Editing, means find out the errors in writing, such as spelling, punctuation, etc.

O’Donnel and Paiva (1993) describe the process of writing as a spiral process. It consists of a series of flexible activities in which a writer may start with writing or thinking, and plan before or while writing. A writer may do each stage many times, until he arrive at the final product of the text.

\section{B. FINDINGS}

1. The importance of Following the Process of Writing

Several research have tried to prove the effectiveness of the process of writing to develop students' writing skill. Ho (2006) conducted a research on the effectiveness of using process approach in writing to primary school students of upper level and lower level 
through pre and post test, questionnaire, interview, and observation. Her research found that process writing was able to develop the writing abilities and students' attitude towards writing in all levels of students. Hasan \& Akhand (2010) in their research combine the product approach and the process approach to teach ESL students in Bangladesh. The research revealed that the combination of the two approaches facilitate students to do writing tasks. Badger and White (2000) in Yan (2015) combine the process approach and the genre approach which he called process genre approach in their study. They reported that this approach helped students study the relationship between purpose and form for a particular genre while they follow the stages in process writing: prewriting, drafting, revising, and editing. Using these steps develops students' awareness of different text types and of the composing process.

\section{The Application of Prewriting Strategies to Develop Students' Interest in Writing}

Teacher can use process approach to help students develop their writing skill by actively involving them in all the stages: prewriting, drafting, revising, and editing. Prewriting as the initial stage in process writing might be very interesting if they are presented in various activities. Teacher then should be very creative to design prewriting activities which are interesting for the students, not only for the primary school students but also for the university students. There are several interesting activities that can be done before students write their text, such as asking questions, discussing an interesting topic, taking notes, free writing, clustering, brainstorming, grouping, doing buzy group, outlining, completing notes based on pictures, making a list, making idea map, categorizing, and classifying (Oshima and Hogue, 1997; Harmer, 2004, Huizenga, et al.,1990).

Harmer (2004) argue that the activities will beinteresting andeffective if they are done in group. The use of pictures also makes the prewriting activities more enjoyable for the students such as those presented by Huizenga, et al., (1990). Teacher can choose the activities that are suitable for the students' level.

The following are the examples of the activities and the application in the classroom: a. Asking Questions

Asking questions can be done to generate ideas to write on a specific topic. Pictures can be used as a media, for example when a teacher assigns his/her students to write about people. The picture is showed to the students and some questions related to the person in the picture are asking, such as "what kind of work does this person do?", "How old is he (she)?, "Where does he (she) live?", "What other facts do you know about this person?", "What outstanding characteristic or ability does this person have?|, What unfavorable quality does this person have?", "How has this person influenced other people in either a positive or a negative way?", "Which age group of people admire this person the most?", "Do you admire him (her)? Why or why not?" (Oshima and Hogue, 1997). Students answer the questions together and take notes the answers. Then, based on the notes, they compose a 
paragraph about a famous person in which the information are taken from the answer of the questions.

This activity will be very interesting if the picture is a person the students know well. Teacher can choose one or several artists that the students often see on TV, sport man, politician, or other person the students are familiar with.

b. Discussing

Discussion can be choosen as one of the activities in prewriting stage to help students develop their topics. Discussion involves some activities auch as discussing issues, eliciting and sharing (Harmer, 2004). Teachers can manage students to do discussion before they write their topics by eliciting words, pharase, or sentences that relate to the topics to use in their paragraph from the students. If teachers ask students to work in group, each group can share important words, phrases, or sentences that can be used by the other group.

For the children, discussion can be done to write the end of a story. Teachers can ask students to read a story and have them discuss the end of the story. If this is done as a group work, each group may have a different end. This activity will raise chiildren' enthusiasm towards narrative story.

c. Taking Notes

Taking notes might be done to get important news/data/information of a particular topic. A student can be act as a reporter and interview some people to get ideas on what he is going to write. Huizenga (1990) gives an example of this technique: A reporter of a small town newspaper visited the scene of a car accident and toke some notes while interviewing the driver and the police.

d. Free writing

Free writing is often used to generate ideas on a particular topic of a narrative writing (Oshima and Hogue, 1997).. Here, the students are asking to write freely without stopping for a specific amount of time. They do not need to pay attention on their sentence structure, punctuation marks and capitalization, and even the choice of words they use. The main objective of this activity is to make students write as long as possible sentences.

Oshima and Hogue (1997) argue that the student can do freewriting to find a good topic to write. The following example of student's freewriting shows this:

A Memoarable Event in My Live

I'm supposed to freewrite for ten minutes about a memorable in my life. I don't know what to write about. Maybe my brother's boat accident. We were so scared. We thought he was going to drown. He was trapped under an overturned boat and didn't have any air to breathe.But it ended all night. He was rescued and only had a broken arm. What else can I write about? Oh! I know. A day I will always remember was theday I left my country to come to the United States. That was a sad/happy day. I felt happy and sad at the same time. Maybe I should write about 
something happy. Our family vacation last summer was fun. We drove to the coast and camped for a week on the beach. Then there was the day the earthquake happened. Now that was definitely a memorable event. I will never forget it. It was at home with my older sister and little brother...

e. Mind Map

When teachers ask his students to do mind map, students write the topic sentence of his writing at the center of a paper and then generate several ideas from that (Harmer, 2004). Oshima and Hogue (1997) named this prewriting strategy as clustering.

Mind map is a good technique to use in prewriting stage since it is interesting especially for the students who like to learn visually. Mindmap can expand their ideas and make them specific. Specific topic eases students to write effective paragraph. Harmer (2004) gives one example of mind map with the topic holiday as shown below:

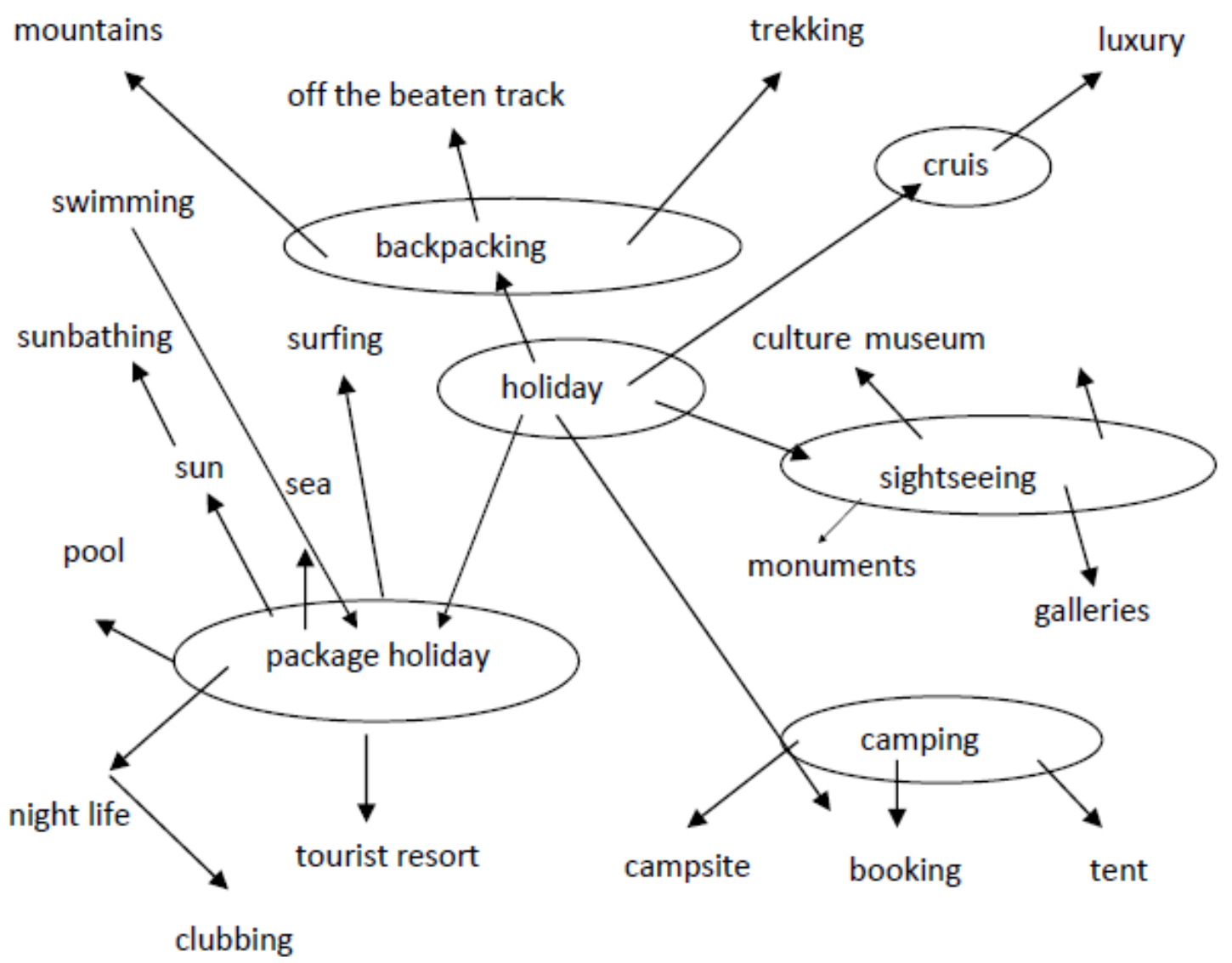

As the mindmap shows, the general topic holiday can be classified into several specific topics: backpacking holiday, sightseeing holiday, package holiday, and camping. Students can choose to write one of these topics and they will write more easily the specific topic rather than they choose to write the general topic, holiday. 
f. Brainstorming

Brainstorming is another activity that can be done to generate ideas on specific topic. When students brainstorming, they are asked to think of everything comes to their mind about the topic they are going to develop and write them down. Oshima and Hogue (1997) list the steps of doing brainstorming as follows:

1. Write down your topic.

2. Note down everything that comes in your mind about it.

3. Use words, phrases, or sentences. Don't pay attention to the mistakes in ideas order, mechanics, grammar, and spelling.

4. Keep writing whatever comes in your mind until you run out of ideas.

The following is one example of brainstorming of a topic shopping in the mall.

Luxurious building

The first time I come to the mall

Expensive price

Glass window

Beautiful shop keepers

Lift

Esclalator

We don't have much money

Sightseing

Bookstore

Fastfood restaurants

Brainstorming activity will be more interesting when it is worked in group. Lots of students brainstorm will generate many ideas than one student does. Teachers can divide the class into several groups, and each group will brainstorm for a specific topic.

\section{g. Grouping}

Grouping is used in longer text/ writing such as essay and research paper which has large and complex topic. To organize the complex/topic, the ideas are organised by grouping them together and discussing each group in a different paragraph (Oshima and Hogue, 1997). As the other technique in prewriting stage, grouping is best done in group. The following is the example of grouping.

A. Divide the following list of words into categories according to the chart. Write each word under the appropriate category.

Indonesian Television Programs

Metro Hari Ini Liputan 6 Siang Celebrity on Vocation Laptop Si Unyil

Jejak Petualang My Trip My Adventure Masakan Nusantara Fokus Siang

Resep Warisan Si Bolang Koper dan Ransel Ala Chef 


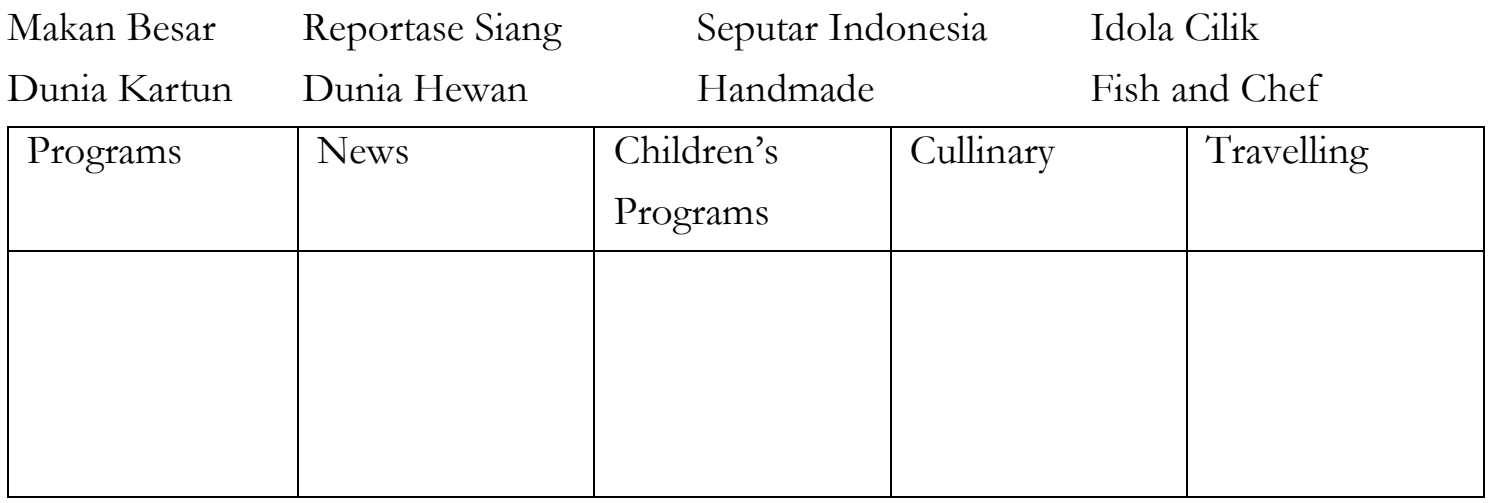

B. Make a list of Indonesian food and drinks that you and your classmates like to eat. Indonesian Food and Drink

h. Doing Buzy Group

As the name suggests, bussy group is done in group. Harmer (p.87) states that bussy group is done by generating ideas, reactions, cues, or opinions quickly and informally. Teachers can ask students to give five reasons why they like to shop in mall rather than in traditional market or why they like to go to public universityrather than private university, and ask them to explain them quickly.

Buzy group is one of effectiwe way of generating ideas before writing the draft. Harmer (1994) argues that this strategy can help students get more ideas on the topic they want to develop. When this is done in group, each group may have different ideas to another group.

i. Outlining

Outline means make a list of the main points of the topic to develop/write (Huizenga, et al., 1990). When we write an outline for an instruction, the main points must/should be listed in order/chronologically such as the following example:

1. Buy a small gift.

2. Be on time!

3. Comliment your host.

4. Don't stay too long.

5. Say thank you.

This is an otline for an instruction paragraph on a topic advice to a friend on how to feel comfortable at a dinner party in U.S. The students then use the outline to write the draft of his instruction as in the following: 
How to Feel Comfortable at an American Dinner Party

Feeling comfortable at an American Dinner Party is not difficult if you follow these instruction. First, you should buy a small gift such as flowers, candy, or wine for your host or hostess. Second, arrive on time. Is the dinner enggagement is for 7:00, don't arrive at 7:15 without calling. Next, during dinner, be sure to compliment your host or your hostess on the meal. After you finish eating, you should not more than a few hours. Finally, thank your host or hostess for the dinner when you leave.

j. Writing Based on Pictures

Writing might be very interesting for students if it is combined with pictures. For example, a student is going to write a procedure of how to take a cash in an authomatic teller machine, he will write the steps based on the pictures available/given. This is the example:

k. Making A list

Making a list can be done when students are going to write an opinion paragraph explaing reasons. Students list their reasons and add some details to supports their reasons. An example of this technique is made by Huzenga, et al., 1990) as in the following:

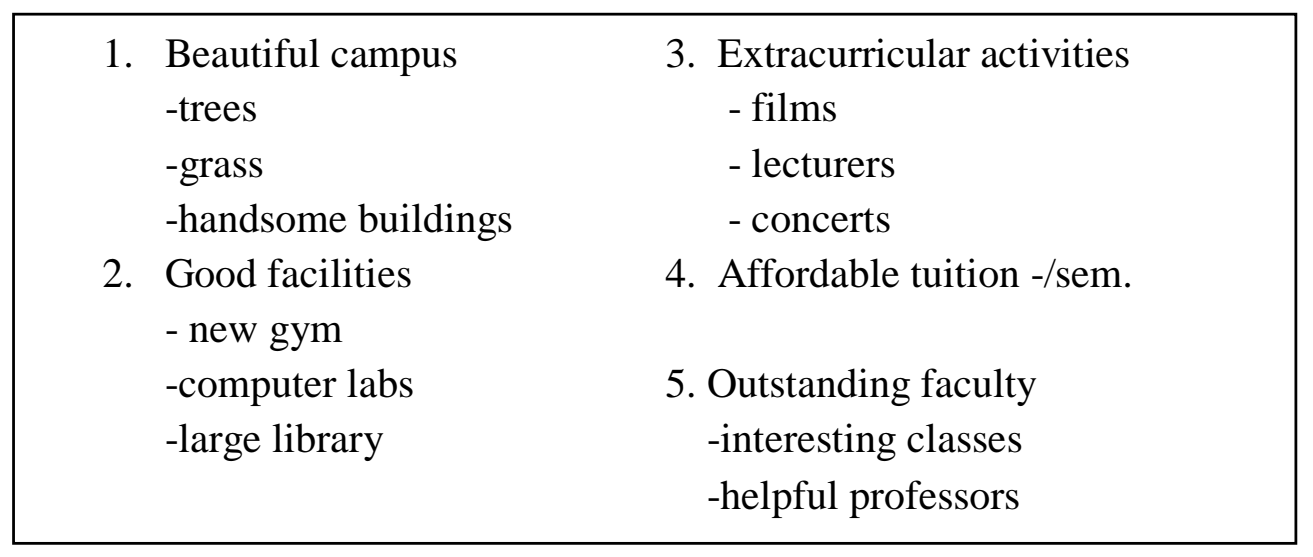

In the example shown above, the writer wants to write a text on why Blake College is very popular to students. Before writing, he listed several reasons that make Blake College very popular and added some details to back up his reasons. When he writes his paragraph he uses the reasons and the details.

\section{Comparing and Contrasting}

Before writing an essay to compare one thing to another, a teacher may ask students to organize their ideas according to the differences and similarities of the things to get ideas. To write a topic comparing city and village for example students may list the similarities and differences of the two places as in the following chart: 


\begin{tabular}{|ll|}
\hline CITY & VILLAGE \\
Difference & \\
-crowded & -quiet \\
-many high buildings & -no high building \\
-air polluted & -fresh air \\
-there is mall & -no mall \\
Similarities & \\
-They both have schools & \\
-They both have market & \\
-They both have public health center & \\
\hline
\end{tabular}

After completing the list of the similarites between city and village, students may develop their essay based on the ideas in chart.

\section{CONCLUSION}

Writing teachers should be creative to make interesting activities to help students improve their writing skill. Creating interesting prewriting activities is one way to engage students' to writing activities. There are plenty options of activities teachers can present to students; some of them have been tested the effectivity in writing classrooms: asking questions, discussing an interesting topic, taking notes, free writing, clustering, brainstorming, grouping, doing buzy group, outlining, completing notes based on pictures, making a list, making idea map, categorizing, and classifying. The use of prewriting activities as a part of a process of writing have been proved effective to improve students' writing skill by some reasearchers.

\section{REFERENCES}

Mukminatien. 2004. Engaging EFL students in Indonesia with Athentic Tasks: Possibilities within Limitations. In English Language Teaching in East Asia Today. Changing Policies and Practices. Second Edition. Ho Wah Kam and Ruth YL Wong, eds. Singapore: Eastern Universities Press.

Yan, Guo. 2014. A process Genre Model for Teaching Writing. English Teacging Forum. Volume 43. No.4. Bureau of Educational and Cultural Affairs. Office of Engliah language Program. 
O’Donnel, Teresa D. And Judith L. Paiva. 1993. Independent Writing. Second Edition. USA: Heinle \& Heinle Publishers.

Md. Kamrul Hasan and Mohd. Moniruzzaman Akhand. 2010. Approaches to Writing in ESL/EFL Context : Balancing Product and Process in Writing Class at Tertiary Level. Journal of NELTA Vol. 15 No. 1-2. Desember 2010. Retrieved on July 2nd, 2014.

Brown, et al. 1984. Grammar and Composition. Boston: Houghton Mifflin Company.

Hadley, Alice Omaggio. 1993.Teaching Language in Context. Boston: Heinle and Heinle Publishers.

Belinda Ho. Perspectives: Working Papers in English and Communication17(1) Spring 2006 Osima, Alice and Ann Hogue. 1997. Introduction to Academic Writing. Second Edition. New York: Longman.

Huizenga, John, C.B.Snellings, and Gladys Berro Francis. 1990. Basic Composition for ESL. An Expository Workbook. Third Edition. US: Heinle Thompson

Harmer, Jeremy. 2004. How to Teach Writing. England: Pearson Education Limited. 